\title{
Development of a multiplex PCR assay for rapid and simultaneous detection of rubber tree pathogens Phytophthora spp. and P. palmivora
}

\author{
Nion Chirapongsatonkula, $^{\mathrm{a}, *}$, Kittichon U-taynapun ${ }^{\mathrm{b}}$, Thitikorn Chanwun ${ }^{\mathrm{c}}$, Nunta Churngchow ${ }^{\mathrm{a}}$ \\ a Department of Biochemistry, Faculty of Science, Prince of Songkla University, Hat-Yai, \\ Songkhla 90110 Thailand \\ b Department of Fisheries, Faculty of Agriculture, Rajamangala University of Technology Srivijaya, \\ Nakhon Si Thammarat 80110 Thailand \\ c Faculty of Science and Technology, Rajamangala University of Technology Srivijaya, \\ Nakhon Si Thammarat 80110 Thailand
}

*Corresponding author, e-mail: nion.c@psu.ac.th,nim_nion@hotmail.com

Received 29 Jan 2015

Accepted 20 Jul 2015

\begin{abstract}
Phytophthora spp. cause devastating effects on crops and natural ecosystems worldwide. In Thailand, P. palmivora is an important pathogenic species of the rubber plant (Hevea brasiliensis), reducing latex production. This study aimed to develop a PCR-based method to rapidly and simultaneously detect the genus Phytophthora and P. palmivora. A single round nested multiplex PCR with 4 primers, Phy1s/Phy2a/Pal1s/Pal2a, and a single round seminested multiplex PCR using 3 primers, Phy1s/Phy2a/Pal2a, were established. The obtained PCR products of 1025 bp and 650 bp represent the ITS1-5.8S-ITS2-28S region of the genus Phytophthora and P. palmivora, respectively. By using various amounts of DNA of a positive strain P. palmivora KBNM 9 and the vector containing ITS region as templates, the sensitivity of these methods was compared to the simple PCR. The single round semi-nested multiplex PCR was applied for the detection of P. palmivora in infected rubber leaves and soil as well as the leaves and bark collected from planted areas. The results of application and the sensitivity test using the DNA of $P$. palmivora mycelium are in agreement. Only one band of 650 bp representing the genus Phytophthora and P. palmivora was detected at low template number. The DNA from severe symptom-exhibiting and dehydrated leaves, however, showed negative results comparable to the classical isolation method that showed no Phytophthora and P. palmivora growth on selective media. This technique may be used to detect and manage Phytophthora infection in important crops.
\end{abstract}

KEYWORDS: internal transcribed spacer, molecular diagnosis, PCR-based method, plant pathogen, single round seminested multiplex PCR

\section{INTRODUCTION}

Hevea brasiliensis (Wild.) Muell.-Arg. or the rubber plant is an economically important crop in Thailand since its latex is a major export. At present, Southeast Asia-especially Thailand, Indonesia, and Malaysia-are the main sources of natural rubber. A consequence of the frequent tapping to collect latex is that infections occur at the tapping wound sites. This problem is common in the southern part of Thailand where the humidity and temperature are high and conducive for pathogen growth and disease development. In Thailand, RRIM600 is the commonly used plantation cultivar because of its high-yield of latex but this cultivar is highly susceptible to Phytophthora pathogens.

Phytophthora leaf disease, caused by members of the oomycete Phytophthora spp., is by far the most important disease of the rubber tree. Phytophthora spp. which are pathogens of the rubber tree include P. palmivora, $P$. botryosa, P. heveae, $P$. meadii, and $P$. parasitica. In the south of Thailand, $P$. palmivora and $P$. botryosa are the most frequently isolated pathogens that cause black stripe, green pod rot, and abnormal leaf fall ${ }^{1}$. P. palmivora attacks the petioles, causing mature leaves to fall prematurely and attacks the tapping surface reducing latex production.

A rapid and accurate microbial identification method is essential for an inspection and survey 
program that will allow for an early detection of any pathogen. Conventionally, diagnosis of the Phytophthora disease has been performed by isolation of pure cultures of Phytophthora from diseased plants followed by identification based on morphological characterization. A definitive diagnosis of a plant pathogen using these traditional tests requires substantial experience in species differentiation within the genus Phytophthora. Moreover, there are difficulties in using phenotypic taxonomic characteristics since there is overlapping among some species, and significant variations regularly occurred among isolates of the same species ${ }^{1-3}$. Nowadays molecular methods allow more accurate species identification and detection of the pathogens.

Many species of Phytophthora can now be identified using their unique DNA sequences in the internal transcribed spacer (ITS) regions of their nuclear ribosomal DNA (rDNA) repeat region ${ }^{4-7}$. Recently, polymerase chain reaction (PCR) has been used extensively for the detection of plant pathogens ${ }^{8-10}$. There are several advantages of PCR-based detection methods over the traditional diagnosis methods; for example, microorganisms do not need to be cultured, it is more reliable, sensitive, and rapid ${ }^{3}$. The PCR-based methods include conventional PCR and quantitative real-time PCR. These methods have been reported as being effective for a number of Phytophthora species ${ }^{5,11-13}$. Nested PCR, a two-step system in which the first round PCR product is subjected to a second PCR amplification, is widely used to detect fungal plant pathogens due to its greater specificity ${ }^{14}$. The sensitivity of this technique also allows the detection of the target pathogen in minute amounts of infected material $^{15,16}$. This method however is time consuming, expensive and labour intensive since it requires separate PCR reactions and additionally increases the risks of false positive due to cross contamination $^{3}$. Multiplex PCR approach is a tool to detect several pathogens simultaneously and reduce the time spent, costs, and contamination risk. Multiplex PCR utilizes a single reaction with several primer pairs, each generating an amplicon that can be separated and visualized through electrophoresis ${ }^{17}$. This technique has been extensively applied in plant pathology as it permits the identification of more than one target in a single reaction ${ }^{6,18,19}$.

PCR-based methods have been utilized worldwide in order to identify and detect $P$. palmivora in orchids ${ }^{20}$, in important Australian plants ${ }^{5}$, in coconut $^{21}$, and in citrus ${ }^{22}$. Rapid identification and diagnosis of the major Phytophthora species in particular P. palmivora is however limited. The aim of this study was to develop a PCR-based assay to detect Phytophthora spp. and specifically P. palmivora. This was attempted by developing a single round semi-nested multiplex PCR method to assist in the early diagnosis of rubber disease caused by Phytophthora spp. and to verify simultaneously in one reaction that $P$. palmivora was the causative species.

\section{MATERIALS AND METHODS}

\section{Phytophthora spp. and fungal culture}

Two isolates of Phytophthora spp., P. palmivora named KBNM 9, previously isolated from rubber trees showing disease symptoms ${ }^{23}$, and $P$. botryosa, were provided by the Songkhla Rubber Research Center, Songkhla, Thailand. P. parasitica was kindly provided by the Department of Plant Science, Faculty of Agriculture, Rajamangala University of Technology Srivijaya, Nakhon Si Thammarat, Thailand. Penicillium funiculosum (TISTR 3563), Aspergillus niger (TISTR 3254), Fusarium solani (TISTR 3436), and Colletotrichum gloeosporioides were obtained from the Thailand Institute of Scientific and Technological Research, Thailand. For the isolation of DNA, each isolate was grown in potato dextrose broth (PDB, Difco Laboratories) at $25^{\circ} \mathrm{C}$ for 7-10 days. The mycelia were harvested and frozen at $-80^{\circ} \mathrm{C}$ until used.

\section{Preparation of zoospores of $P$. palmivora}

Zoospore suspension of $P$. palmivora was prepared following the method of Chirapongsatonkul et $\mathrm{al}^{24}$. Plugs cut from the edge of the culture were transferred to $a V_{8}$ agar plate, a medium containing vegetable juice produced by Campbell Soup Company. Five days later, the growing mycelium was chilled using sterile water $\left(8-10^{\circ} \mathrm{C}\right)$ for $15 \mathrm{~min}$ and zoospores were collected $30 \mathrm{~min}$ later. The amount of zoospore was counted using haemocytometer. The concentration of zoospore suspension was adjusted to $5 \times 10^{5}$ zoospores $/ \mathrm{ml}$ with sterile distilled water. The suspensions were used within $30 \mathrm{~min}$, before encystment and germination could occur.

\section{Plant materials and soil samples}

Detached healthy rubber leaves from 3 individual plants were placed in a Petri dish containing $10 \mathrm{ml}$ of the zoospore suspension or sterile distilled water as a control. After the abaxial surface of each leaf was placed facing the zoospores for $1 \mathrm{~h}$, all leaves were rinsed with sterile distilled water and placed 
on a moist Whatman paper. The inoculated leaves were kept at $25^{\circ} \mathrm{C}$ under $12 \mathrm{~h}$ of daylight. The leaves were collected at 12 and $24 \mathrm{~h}$ and kept at $-80^{\circ} \mathrm{C}$ for DNA extraction.

Twenty of 6-week-old rubber seedlings were divided into two groups, untreated control and zoospore-treated group. The seedlings were sprayed with the zoospore suspension or sterile distilled water. All seedlings were kept in a moist controlled plastic bag, with a relative humidity of $70-80 \%$, at $25^{\circ} \mathrm{C}$ under $12 \mathrm{~h}$ of daylight to support the pathogen growth. The leaves were collected and pooled from 5 plants at 12 and $24 \mathrm{~h}$ after treatment and kept at $-80^{\circ} \mathrm{C}$ for DNA extraction.

Commercial soil (Din Lum Duan), bought from the garden supplies shop, was sterilized by autoclaving before being divided for two treatments. For the P. palmivora treatment, 10 plugs cut from the edge of the growing mycelium after being cultured on PDA for 7 days were inoculated in $25 \mathrm{~g}$ of sterilized soil. Soils were kept in the moist controlled plastic bag for one week. Agar plugs were removed from the infested soil prior to storing the soil at $-80^{\circ} \mathrm{C}$ for DNA extraction.

Diseased plant materials from rubber seedlings and mature plants were collected from natural rubber nurseries and plantations in the southern part of Thailand. All samples were carefully transferred to the Department of Biochemistry, Faculty of Science, Prince of Songkla University, Thailand and kept at $-80^{\circ} \mathrm{C}$ until being used for DNA extraction.

\section{Isolation of DNA}

DNA of the mycelia of all fungi, plant tissues, and soil (50-100 mg of each sample) was extracted and purified using DNAzol (Invitrogen, USA) and NucleoSpin Plant II Kit (Macherey-Nagel, Germany) according to the supplied protocol from the manufacturer. DNA of $P$. infestans was kindly provided by Ms Waraporn Prakob, Department of Entomology and Plant Pathology, Faculty of Agriculture, Chiang Mai University. The concentration of DNA was determined spectrophotometrically using MaestroNano Micro-Volume Spectrophotometer.

\section{Primers for Phytophthora spp. and P. palmivora}

Two sets of primers, specific to the Phytophthora genus (Phy1s/Phy2a) and to P. palmivora (Pal1s/ Pal2a), used throughout this study were based on the report of Tsai et $\mathrm{al}^{20}$. The nucleotide sequences of primers and expected binding locations are shown in Table 1. The primer used as an internal
Table 1 PCR primers used in this study.

\begin{tabular}{llll}
\hline Target & Name & Primer sequence $\left(5^{\prime}\right.$ to $\left.3^{\prime}\right)$ & Loc. \\
\hline Phytophthora & Phy1s & ACTTTCCACGTGAACCGTATCA & ITS1 \\
spp. & Phy2a & GCACGAGCCACTCAGGGATG & 28S \\
P. palmivora & Pal1s & CACGTGAACCGTATCAAAACT & ITS1 \\
& Pal2a & CAATCATACCACCACAGCTGA & ITS2 \\
Actin of & actF & CACCACCACTGCCGAACGGG & Actin \\
H. brasiliensis & actR & ACGGTCTGCAATGCCAGGGA & \\
\hline
\end{tabular}

marker in the rubber plant tissue was designed from the actin gene (GU270586.1) of H. brasiliensis.

\section{Multiplex PCR for Phytophthora spp. and P. palmivora detection}

Single round nested and semi-nested multiplex PCR reactions were carried out using the set of primers Phy1s/Phy2a/Pal1s/Pal2a and Phy1s/Phy2a/Pal2a, respectively. Approximately 2 ng of DNA extracted from $P$ palmivora was used as a template. The PCR reactions were performed in $25 \mu$ l reaction using EmeraldAmp GT PCR Master mix (Takara Bio Inc). The PCR condition used was as follows: denaturation at $94^{\circ} \mathrm{C}$ for $5 \mathrm{~min}$, followed by 30-35 cycles of $1 \mathrm{~min}$ at $95^{\circ} \mathrm{C}, 1 \mathrm{~min}$ at $55^{\circ} \mathrm{C}, 1 \mathrm{~min}$ at $72^{\circ} \mathrm{C}$, and a final extension at $72{ }^{\circ} \mathrm{C}$ for $10 \mathrm{~min}$. PCR products were analysed by electrophoresis on $2 \%$ (w/v) agarose gel with $0.5 \mu \mathrm{g} / \mathrm{ml}$ ethidium bromide in $1 \times$ TAE. The amplicon sizes were estimated by comparison with a 100 bp Plus DNA ladder (Vivantis Technologies Sdn. Bhd). To determine the suitable primer concentration to increase the efficiency of the single round semi-nested multiplex PCR, a gradient of primer concentrations from 0.4 to $0.05 \mu \mathrm{M}$ were tested in $25 \mu \mathrm{l}$ PCR reaction containing all components except for DNA template. PCR products were analysed by electrophoresis.

To confirm and recheck the detected product, the amplified fragments were cut from the gel, purified using QIAquick Gel Extraction Kit (Qiagen), ligated to pGEM-T Easy vector (Promega) and transformed into Escherichia coli Top10 cells. Purified plasmids were bidirectional sequenced directly, using the dye-terminator cycle-sequencing reaction (Applied Biosystems). The nucleotide sequences were compared with the fragments amplified separately using the primer pair covering the Phytophthora genus (Phy1s/Phy2a), and those specific to P. palmivora (Pal1s/Pal2a).

The specificity of the single round semi-nested multiplex PCR was examined by amplification of the DNA of all fungal samples including those of the positive and negative controls. PCR reaction using 
the DNA from healthy rubber plant tissues was carried out to check whether the primers could amplify other non-target genes from the host plant. The actin primer pair (actF/actR), amplifying actin gene of rubber plant, was used as an internal control.

\section{Sensitivity test}

The sensitivity of the single round semi-nested multiplex PCR was determined by comparing with the simple PCR and the single round nested multiplex PCR. The amount of target DNA was varied at 40,8 , and $4 \mathrm{ng}, 800,400$, and $40 \mathrm{pg}$. Ten-fold serial dilutions $\left(1-10^{-6}\right)$ of the recombinant vector containing ITS region of $P$. palmivora were also used as templates. The PCR condition for all reactions was as previously described.

\section{Detection of $P$. palmivora in the infected rubber leaves and soil}

To ensure that the single round semi-nested multiplex PCR protocol can detect Phytophthora spp. and $P$. palmivora in infected plant tissues and soil, the method was used to amplify the DNA samples extracted from the detached rubber leaves, seedlings, and soil. Three independent series of experiments were performed and each experiment was assayed at least in triplicate. Moreover, the DNA extracted from plant materials collected from the naturally planted rubber trees expressing leaf fall or black stripe were also used as templates. Each sampling material was extracted for DNA and tested in triplicate. The single round semi-nested multiplex PCR was performed by using AccuStart II GelTrack PCR SuperMix (Quanta BioSciences) followed the previously described condition.

\section{RESULTS}

\section{Single round nested multiplex and single round} semi-nested multiplex PCR

The primers used throughout this study, Phy1s/ Phy2a and Pal1s/Pal2a, to identify and detect Phytophthora spp. and $P$. palmivora, respectively, were according to Tsai et $\mathrm{al}^{20}$. These primers have been validated for the specificity by testing them with several Phytophthora spp. and other related genus. Based on the alignment with the sequences submitted to the NCBI database by nucleotide BLAST analysis and CLUSTALW (BIOEDIT), the binding locations and amplified product sizes of each primer within the ITS1-5.8S rDNA-ITS2-28S rDNA region of Phytophthora spp. and P. palmivora are shown in Fig. 1.

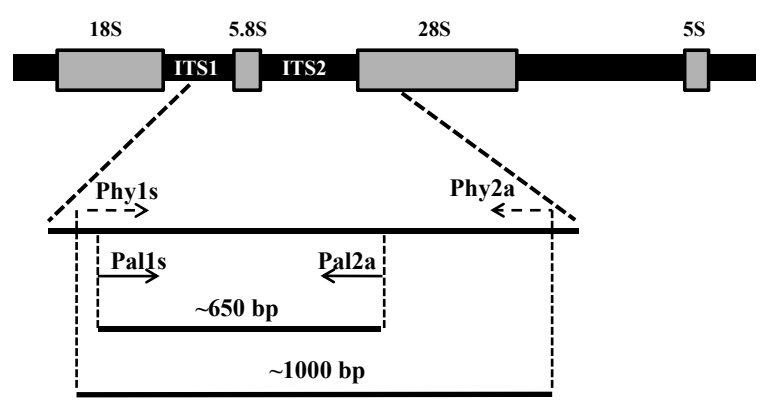

Fig. 1 The sites that the primers Phy1s, Phy2a, Pal1s, and Pal2a match on the rDNA of P. palmivora and the predicted PCR product sizes obtained by amplifying with these primer sets. Dash arrows indicate Phy1s and Phy2a while thick arrows refer to Pal1s and Pal2a.

By means of primers used, our multiplex PCR was similar to the nested PCR but there was no need to perform the first and the second amplifications separately as in normal nested PCR. It was thus named single round nested multiplex PCR. In this condition, the primer sets, i.e., Phy1s/Phy2a/Pal1s/Pal2a with equal concentrations, were used in the unique PCR reaction. Two bands approximately $1000 \mathrm{bp}$ and $650 \mathrm{bp}$ were revealed; however, the smaller band seemed to be better amplified when using $2 \mathrm{ng}$ of DNA of $P$. palmivora mycelia as the template (Fig. 2a, lane 1). Since the match site of Phy1s on the ITS region is very close and covered that of Palls (6 bp upstream of the Pal1s binding site), Pal1s was then eliminated and 3 primers, i.e., Phy1s, Phy2a, and Pal2a, were used to perform the single round seminested multiplex PCR. Moreover, to obtain the clear two bands with equal intensity, the single round semi-nested multiplex PCR was carried out with the gradient concentrations of each primer when the DNA template was fixed (Fig. 2a). The equal bands could be observed in lanes 4, 5, and 6; however, the intensity of each band was slightly different. Accordingly, the suitable final concentration of the primers which was used in the further studies were $0.4 \mu \mathrm{M}, 0.4 \mu \mathrm{M}$, and $0.075 \mu \mathrm{M}$ for Phy1s, Phy2a and Pal2a, respectively.

To determine the specificity of the single round semi-nested multiplex PCR condition, the obtained PCR products of approximately $1000 \mathrm{bp}$ and $650 \mathrm{bp}$ were purified, cloned, and sequenced. The sequences from these two bands were identical with the resulting bands of $1025 \mathrm{bp}$ and $644 \mathrm{bp}$ amplified by Phy1s/Phy2a and Pal1s/Pal2a, respectively. The nucleotide sequences were deposited at GenBank 


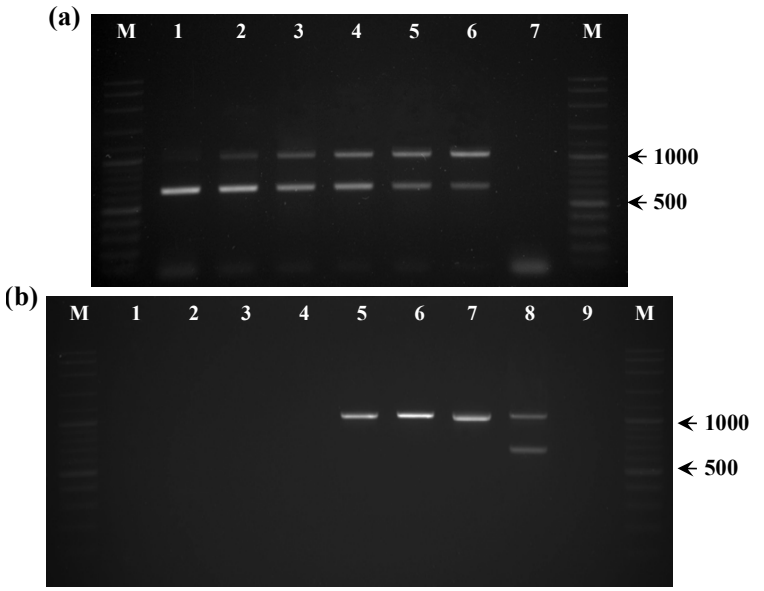

Fig. 2 The single round multiplex PCR. (a) Nested multiplex and semi-nested multiplex PCR were performed using DNA from $P$ palmivora KBNM 9 as the template. Lane 1: single round nested multiplex PCR containing Phy1s/Phy2a/Pal1s/Pal2a at the concentration of $0.4 \mu \mathrm{M}$ each; lanes 2-6: single round semi-nested multiplex PCR using Phy1s/Phy2a/Pal2a as the primer set, the concentrations of Phy1s and Phy2a were fixed at $0.4 \mu \mathrm{M}$ each while the concentration of Pal2a was varied; lane 2: $0.4 \mu \mathrm{M}$; 3: $0.2 \mu \mathrm{M}$; 4: $0.1 \mu \mathrm{M}$; 5: $0.075 \mu \mathrm{M}$; 6: $0.05 \mu \mathrm{M}$; and 7: water control. (b) Specificity of the single round semi-nested multiplex PCR. PCR using DNA from Phytophthora spp. and other fungal isolates as the templates and the primer set Phy1s/Phy2a/Pal2a was performed. Lane 1: C. gloeosporioides; 2: A. niger; 3: Penicillium funiculosum; 4: F. solani; 5: P. botryosa; 6: P. infestans; 7: P. parasitica; 8: P. palmivora; 9: water control; and $\mathrm{M}$ represents 100 bp Plus DNA ladder.

(Accession number: JX863409 and HQ446453). Analysis of the PCR products by Blastn indicated that the fragments carried the ITS1-5.8S-ITS2-28S rDNA region of $P$. palmivora. In addition, the best hits of all sequences were ribosomal ITS sequences obtained from the same species by other laboratories (data not shown). Using the DNA of P. palmivora KBNM 9 as a model, the actual sizes of products from the single round semi-nested multiplex PCR amplified by Phy1s/Phy2a and Phy1s/Pal2a were 1025 and $650 \mathrm{bp}$, respectively.

The PCR reaction was performed using the optimal condition and DNA extracted from four various species belonging to the genus Phytophthora and other fungi as templates. No amplification signal was detected in the reactions using DNA from other fungal isolates. Only one band of around $1000 \mathrm{bp}$ in length was obtained from all tested Phytophthora spp. while two bands (1025 and $650 \mathrm{bp)}$ were revealed when the template was DNA of $P$. palmivora. These results indicated the specificity of the developed detection method (Fig. 2b).

\section{Sensitivity test of the single round semi-nested multiplex PCR}

The sensitivity of the developed single round seminested multiplex PCR was determined by comparing the detection of Phytophthora spp. and P. palmivora using conventional PCR and a single round nested multiplex PCR. The results revealed that all methods could detect $P$. palmivora in a dosedependent manner comparable to the concentrations of the DNA template (Fig. 3). The faint bands, representing the lowest amount of DNA detected, were observed in both simple PCRs at 40 pg of DNA template (Fig. 3a, lane 6 and Fig. 3b, lane 6). For the single round nested multiplex PCR, the smaller bands (sized 650 bp representing the species-specific $P$. palmivora) were thicker and, in addition, when the amount of DNA templates were lower than $4 \mathrm{ng}$, the $1025 \mathrm{bp}$ band (representing the genus Phytophthora) was hardly observed (Fig. 3c, lanes 4-6). The single round semi-nested multiplex PCR showed equal intensity of $1025 \mathrm{bp}$ and $650 \mathrm{bp}$ DNAs in the template ranged between $40 \mathrm{ng}$ and $4 \mathrm{ng}$ (Fig. 3d, lanes 1-3). With low amount of DNA, the smaller band became thicker than those of the larger one (Fig. 3d, lanes 4 and 5). According to the results, the comparative sensitivities of the single round semi-nested multiplex PCR and the simple PCR revealed that both methods showed the same detection limit of $40 \mathrm{pg}$ of template tested.

The sensitivity was tested by using the 10-fold serial-dilutions of the vector containing ITS region of $P$. palmivora. The positive signal was detected at $1-10^{-3}$ dilution by the single round semi-nested multiplex PCR (Fig. 3f) which was similar to those from the simple PCR methods (data not shown). It seems that only one band of 650 bp was observed in the reaction with low amount of template for the single round nested multiplex PCR (Fig. 3e) comparable with the result when using various DNA amounts as templates.

Detection of $P$. palmivora in the infected rubber leaves and soil by the single round semi-nested multiplex PCR

The DNAs extracted from the rubber plants and soil were used as templates to verify whether the developed method can detect $P$. palmivora in the infected materials. The PCR employing the primer 
(a)

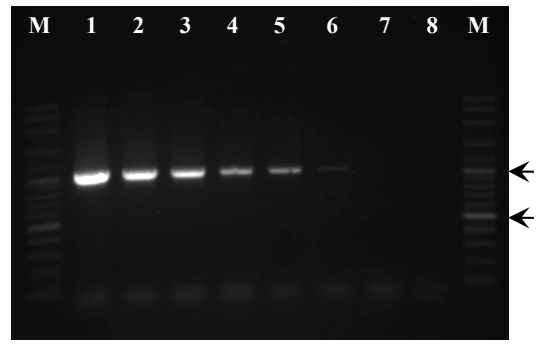

(c)

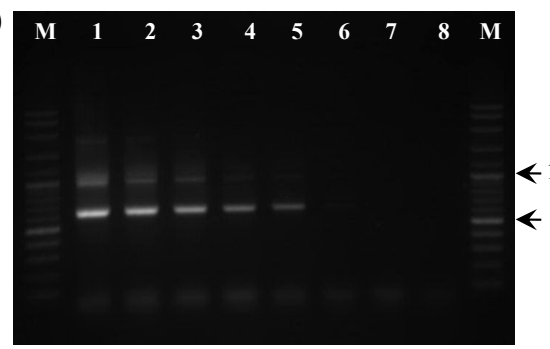

(e)

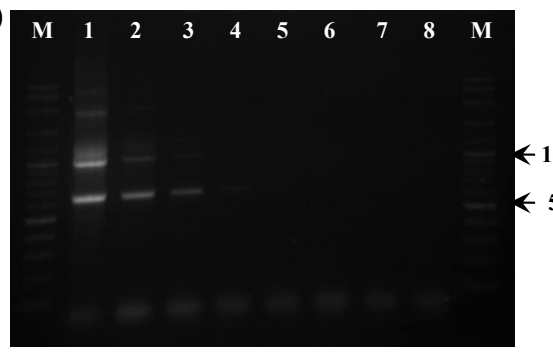

(b)

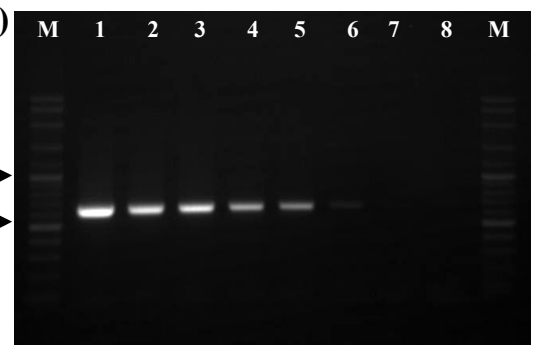

(d)
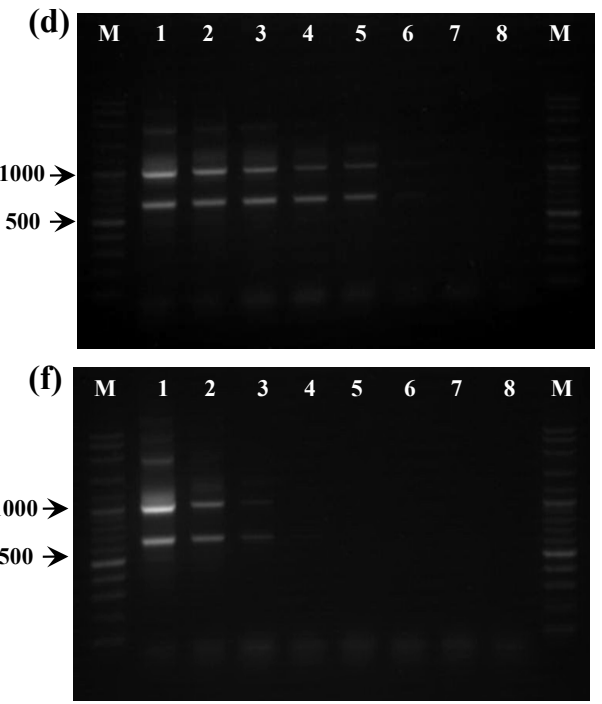

Fig. 3 Sensitivity analysis for P. palmivora detection. Using diluted DNA of P. palmivora as templates; (a) the simple PCR method with primer Phy1s/Phy2a, (b) primer Pal1s/Pal2a, (c) the single round nested multiplex PCR with primer set Phy1s/Phy2a/Pal1a/Pal2a and (d) the single round semi-nested multiplex PCR with Phy1s/Phy2a/Pal2a. Lane 1: 40 ng; 2: 8 ng; 3: 4 ng; 4: 800 pg; 5: 400 pg; 6: 40 pg; 7: 4 pg; 8: water control; and M: 100 bp Plus DNA ladder. Using vector containing ITS region of P. palmivora as templates; (e) the single round nested multiplex PCR and (f) the single round semi-nested multiplex PCR, lane $1: 1 ; 2: 10^{-1} ; 3: 10^{-2} ; 4: 10^{-3} ; 5: 10^{-4} ; 6: 10^{-5} ; 7: 10^{-6}$ copies; 8: water control.

of the actin gene (actF/actR) of the rubber plant was used as a control reaction to confirm an equal amount of DNA in all samples. There was a $650 \mathrm{bp}$ DNA band detected in the $12 \mathrm{~h}$ zoospore treated leaves while two clear bands were present in the zoospore-treated leaves (24 h after treatment) and soil (Fig. 4a). There was however only one faint band of $650 \mathrm{bp}$ visualized in the samples collected from the $12 \mathrm{~h}$ and $24 \mathrm{~h}$ zoospore treated seedlings (Fig. 4b). No visible bands were visualized in the untreated plant samples and soil DNA in the single round semi-nested multiplex PCR.

The DNA extracted from plant materials including leaves from seedlings and mature plants as well as barks collected from the naturally planted rubber trees expressing leaf fall or black stripe were also tested using this semi-nested multiplex PCR procedure. Similar phenomena to those DNA extracted from the controlled inoculation experiment were obtained. The leaves with mild to moderate lesions showed a faint band of 650 bp (Fig. 5). As expected, no visible band was observed in healthy leaf samples. However, a negative result was observed when using the DNA extracted from the dehydrated leaves exhibiting severe symptoms (Fig. 5) and the fallen leaves picked up from the ground, as well as that from the barks (data not shown). This phenomenon was comparable to the conventional culture methods to isolate Phytophthora spp. from the same samples.

\section{DISCUSSION}

The primer sets to validate the detection of Phytophthora spp. and P. palmivora are available ${ }^{20}$, the single round nested multiplex PCR was then developed. There would typically be two bands produced, sizes at $1025 \mathrm{bp}$ and $644 \mathrm{bp}$ when the primer sets Phy1s/Phy2a and Pal1s/Pal2a were used 


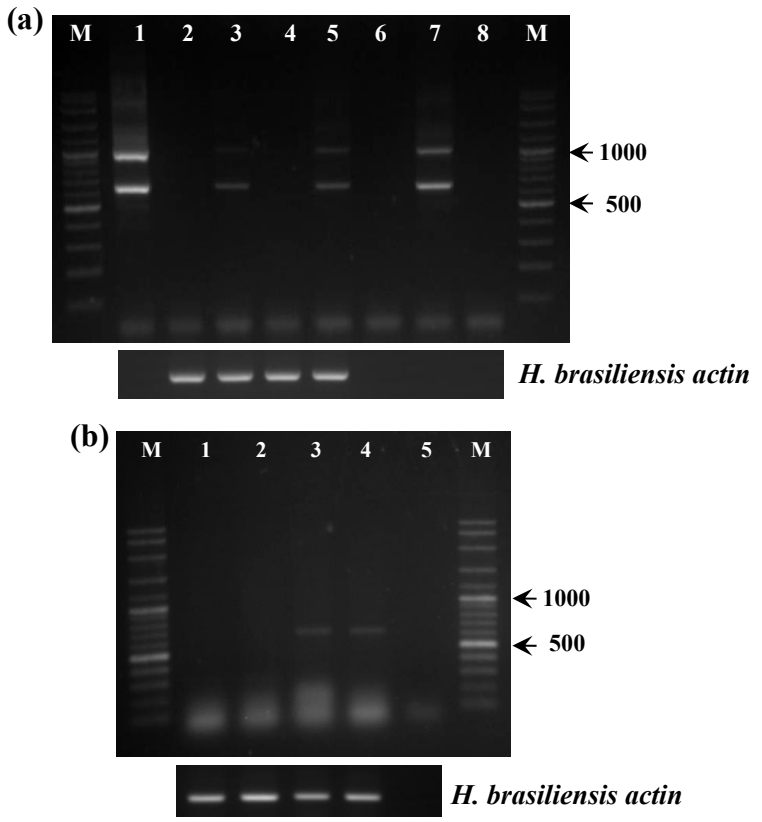

Fig. 4 Detection of $P$ palmivora by single round seminested PCR. The DNA extracted from zoospores treatedand untreated rubber leaves and soil; (a) single round semi-nested PCR was performed (upper panel) and equal amount of DNA was verified using actin gene of rubber plant (lower panel). Lane 1: P. palmivora; 2: $12 \mathrm{~h}$ untreated leaves; $3: 12 \mathrm{~h}$ treated leaves; $4: 24 \mathrm{~h}$ untreated leaves; 5: 24 h treated leaves; 6: untreated soil; 7: treated soil; 8: water; M: 100 bp Plus DNA ladder. (b) The DNA extracted from rubber seedlings, lane 1: $12 \mathrm{~h}$ untreated leaves; 2: $24 \mathrm{~h}$ untreated leaves; 3: $12 \mathrm{~h}$ treated leaves; 4: $24 \mathrm{~h}$ treated leaves; 5: water.

together in the unique PCR reaction. The result showed that the smaller band seemed to be better amplified (Fig. 2a, lane 1). This may be due to the possibility that the PCR product amplified by Phy1s/Phy2a (1025 bp) could also be a template for Pal1s/Pal2a. Another possible reason is that the template bound with these two primer sets are covering the same region, the primer Pal1s/Pal2a could probably better compete and bind to the template. In addition, the smaller-band product may also be amplified by Phy1s/Pal2a. Since the match site of the primer Phy1s on the ITS region is very close (6 bp upstream) and covers that of Pal1s, a single round semi-nested multiplex PCR which eliminates the primer Pal1s was considered to reduce the cost. The primer Phy1s could involve in the amplification of both bands while Phy2a and Pal2a produced either the $1025 \mathrm{bp}$ or the $650 \mathrm{bp}$ band, respec- tively. To obtain the two clear bands with equal intensity in a single round semi-nested multiplex PCR, we found that the final concentration of primer Pal2a should be lower than those of Phy1s and Phy2a. Some studies have recommended avoiding the use of nested primers in multiplex PCRs as there may be either false-positive results due to carryover contamination or false-negative results due to the reaction failure ${ }^{25-27}$. The results showed the specificity of our single round semi-nested multiplex PCR procedure since there was no false-positive or false-negative as no band, only one and two bands occurred when templates were those of other fungi, Phytophthora spp. and P. palmivora, respectively, (Fig. 2b). No PCR band was amplified when using the DNA from rubber plant as a template, suggesting that these primers could not amplify any gene in the tested host genome (data not shown). Moreover, the specificity of this technique was assured by the analysis of the nucleotide sequences of both PCR fragments. These results confirmed and validated the developed PCR procedure and thus supported its application for simultaneous detection of the target pathogens.

The comparative determination of the sensitivity was performed using the developed single round semi-nested multiplex PCR, the conventional PCR and the single round nested multiplex PCR. Various amounts of DNA extracted from the mycelia of $P$. palmivora (40 $\mathrm{ng}$ to $4 \mathrm{pg}$ ) and the 10-fold serial-dilutions of the vector containing ITS region of $P$ palmivora (1-10 $10^{-6}$ dilutions) were used as templates. The results revealed that all methods could detect the presence of $P$. palmivora in a dosedependent manner (Fig. 3). The sensitivity of the single round semi-nested multiplex PCR was similar to those of the simple conventional PCR. The lowest amount of template that could be detected was $40 \mathrm{pg}$ and $10^{-3} \mathrm{pg}$ for extracted DNA and recombinant vector, respectively. When performing the single round nested and semi-nested multiplex PCRs with low templates, the smaller bands (sized $650 \mathrm{bp}$ representing the species-specific $P$. palmivora) were however thicker than those of the $1025 \mathrm{bp}$ bands (Fig. 3c,d). This may be due to the possibility that some larger band could act as a template for producing the smaller one; therefore its band intensity was consequently increased. Non-specific PCR products however could be detected in some conditions especially when the numbers of template were very high (Fig. 3c,d, lanes 1-2, and Fig. 3e,f, lane 1). A few parameters that may cause non-specific products to appear include the concentration of $\mathrm{MgCl}_{2}$, the 

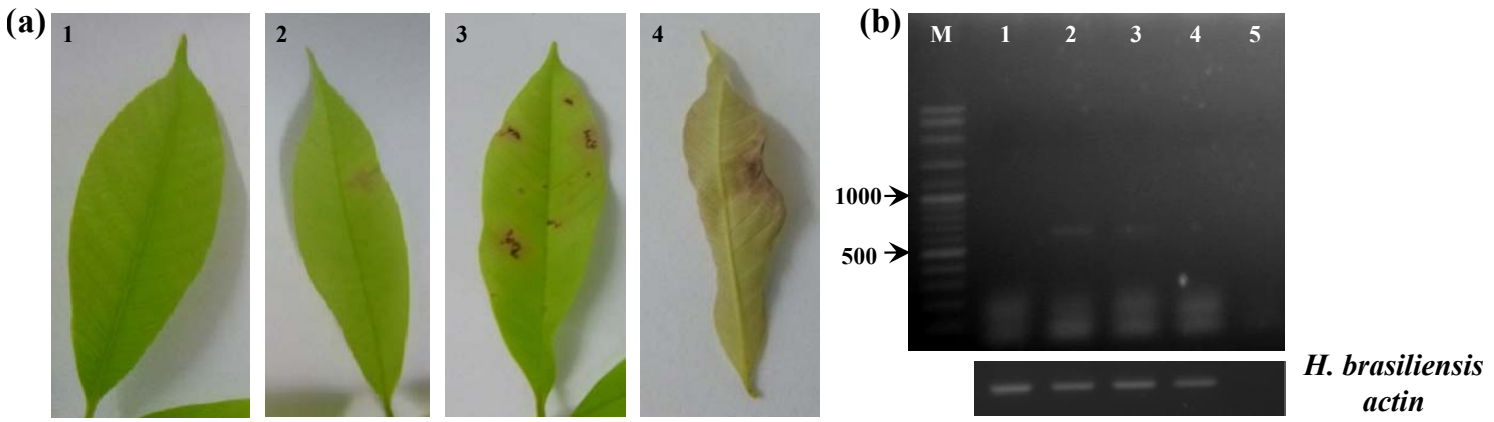

Fig. 5 Detection of P. palmivora in rubber leaves collected from the rubber plantations: (a) healthy (1) and diseased rubber leaves with various symptom levels: mild (2), moderate (3), and severe (4) symptoms taken for DNA extraction; (b) single round semi-nested PCR detection of P. palmivora in healthy and naturally diseased rubber leaves. Single round semi-nested PCR was performed (upper panel) and equal amount of DNA was verified using actin gene of rubber plant (lower panel). Lanes 1-4: DNA of healthy leaf; leaf expressing mild; moderate; and severe symptom, respectively; 5: water; M: 100 bp Plus DNA ladder.

amount of DNA template, number of cycles and annealing temperature, all of which were tested for their effects. Varying the concentration of $\mathrm{MgCl}_{2}$ and annealing temperature showed no effect, while decrease of either template amounts or amplification cycles caused the reduction of non-specific bands correspondingly (data not shown). Thus the crucial factor causing the accelerated accumulation of non-specific products in our single round seminested multiplex PCR could be an elevated concentration of the template combined with the high number of cycles.

The single round semi-nested multiplex PCR protocol could also detect $P$. palmivora in plant materials and soil. The positive results were shown in the inoculated samples; however, there was only a faint band of $650 \mathrm{bp}$ visualized in the some samples (Fig. 4). This observation was comparable with the sensitivity analysis that only smaller band was observed in the condition of small amount of P. palmivora. Even single 650 bp band detected, it hinted that there was the ITS region of $P$ palmivora representing the genus Phytophthora and the species P. palmivora in the DNA template. In addition, the observed bands imply that the amount of pathogen corresponds to the progression of the pathogen growth as seen by the necrosis symptoms and lesions. This detection method was also used to inspect $P$. palmivora in the rubber leaves and barks expressing leaf fall or black stripe or disease-like symptoms collected from naturally planted areas. Single faint band of 650 bp was visually similar to the results obtained from the artificially $P$. palmivora infected leaves. This was also observed in the leaves with mild to moderate symptoms, but not in the severe or dehydrated one (Fig. 5). The results suggested that this PCR procedure can be used to detect Phytophthora spp. and P. palmivora in infected plant tissue and soil. The Phytophthora genus and $P$ palmivora could not be detected in barks and fallen leaf samples from natural environment. Accordingly, no Phytophthora spp. could be grown on selective media, which is considered a conventional method to separate and identify these pathogens. A plausible explanation may be that the materials do not support and hold the pathogen growth. The oomycete Phytophthora species are considered hemibiotrophs since they exhibit lifestyles ranging from obligate biotrophic to necrotrophic; however, their persistence depends on the condition of the host cell ${ }^{28}$. Moreover, it has been demonstrated that biomass of Phytophthora spp. such as P. infestans and $P$. ramorum in infected tissues is generally low ${ }^{29}$. Other possible reason is that the disease expressing materials tested here might not be caused by Phytophthora spp. since diverse pathogens within the same or different genus could induce similar disease symptoms ${ }^{30,31}$.

In conclusion, the developed single round seminested multiplex PCR is a novel strategy providing easy, rapid, and simultaneous detection and identification of Phytophthora spp. and P. palmivora. It is used to identify and detect $P$. palmivora in natural diseased plant materials, soil, and water. Nonetheless, this method may still have a limitation towards its sensitivity limit especially in cases with low number of pathogens, as in soil, water, or trees that have been dead for several years. Those conditions may be difficult for the detection of pathogens. Future adaptation of the technique such as real- 
time PCR or multiplex real-time PCR will allow quantitative measurements of P. palmivora, and may increase the sensitivity of the assay. Further, this diagnostic test may prove valuable in detecting and managing diseases caused by Phytophthora spp. and P. palmivora.

Acknowledgements: This work was supported by a grant for New Researcher from the Thailand Research Fund, Office of the Higher Education Commission, and Prince of Songkla University (project number MRG5480104) and the Faculty of Science Research Fund, Prince of Songkla University. We would like to acknowledge Dr Brian Hodgson for the critical review and valuable comments.

\section{REFERENCES}

1. Erwin DC, Ribeiro OK (1996) Phytophthora Diseases Worldwide, The American Phytopathological Society, APS Press, MN, pp 408-22.

2. Appiah AA, Flood J, Archer SA, Bridge PD (2004) Molecular analysis of the major Phytophthora species on cocoa. Plant Pathol 53, 209-19.

3. Cooke DEL, Schena L, Cacciola SO (2007) Tools to detect, identify and monitor Phytophthora species in natural ecosystems. J Plant Pathol 89, 13-28.

4. Cooke DEL, Duncan JM (1997) Phylogenetic analysis of Phytophthora species based on ITS1 and ITS2 sequences of the ribosomal RNA gene repeat. Mycol Res 101, 667-77.

5. Drenth A, Irwin JAG (2001) Routine DNA based diagnostic tests for Phytophthora, A report for the Rural Industries Research and Development Corporation, Barton, Australia.

6. Winton LM, Hansen EM (2001) Molecular diagnosis of Phytophthora lateralis in trees, water, and foliage baits using multiplex polymerase chain reaction. Forest Pathol 31, 275-83.

7. Chimento A, Scibetta S, Schena L, Cacciola SO, Cooke DEL (2005) A new method for the monitoring of Phytophthora diversity in soil and water. In: S.I.Pa.V XII National Meeting-Reggio Calabria, 29 September1 October 2005-Posters. J Plant Pathol 87, p 290.

8. Martin RR, James D, Lévesque CA (2000) Impacts of molecular diagnostic technologies on plant disease management. Annu Rev Phytopathol 38, 207-39.

9. Martin FN, Tooley PW, Blomquist C (2004) Molecular detection of Phytophthora ramorum, the causal agent of sudden oak death in California, and two additional species commonly recovered from diseased plant material. Phytopathology 94, 621-31.

10. Ward E, Foster SJ, Fraaije BA, McCartney HA (2004) Plant pathogen diagnostics: Immunological and nucleic acid-based approaches. Ann Appl Biol 145, $1-16$.
11. Hayden K, Ivors K, Wilkinson C, Garbelotto M (2006) TaqMan chemistry for Phytophthora ramorum detection and quantification, with a comparison of diagnostic methods. Phytopathology 96, 846-54.

12. Lees AK, Sullivan L, Lynott JS, Cullen DW (2012) Development of a quantitative real-time PCR assay for Phytophthora infestans and its applicability to leaf, tuber and soil samples. Plant Pathol 61, 867-76.

13. Bilodeau GJ, Martin FN, Coffey MD, Blomquist CL (2014) Development of a multiplex assay for genusand species-specific detection of Phytophthora based on differences in mitochondrial gene order. Phytopathology 7, 733-48.

14. Ippolito A, Schena L, Nigro F (2002) Detection of Phytophthora nicotianae and P. citrophthora in citrus roots and soils by nested PCR. Eur J Plant Pathol 108, 855-68.

15. Renker C, Heinrichs J, Kaldorf M, Buscot F (2003) Combining nested PCR and restriction digest of the internal transcribed spacer to characterize arbuscular mycorrhizal fungi on roots from the fields. Mycorrhiza 13, 191-8.

16. Alaniz S, Armengol J, García-Jiménez J, Abad-Campos P, León M (2009) A multiplex PCR system for the specific detection of Cylindrocarpon liriodendri, C. macrodidymum, and $C$. pauciseptatum from grapevine. Plant Dis 93, 821-5.

17. Chamberlain JS, Gibbs RA, Ranier J, Nguyen PN, Caskey T (1988) Deletion screening of the Duchenne muscular dystrophylocus via multiplex DNA amplification. Nucleic Acids Res 16, 11141-56.

18. Schena L, Hughes KJD, Cooke DEL (2006) Detection and quantification of Phytophthora ramorum, $P$. kernoviae, $P$. citricola and $P$. quercina in symptomatic leaves by multiplex real-time PCR. Mol Plant Pathol 7, 365-79.

19. Boureau T, Kerkoud M, Chhel F, Hunault G, Darrasse A, Brin C, Durand K, Hajri A, et al (2013) A multiplexPCR assay for identification of the quarantine plant pathogen Xanthomonas axonopodis pv. phaseoli. J Microbiol Meth 92, 42-50.

20. Tsai HL, Huang LC, Ann PJ, Liou RF (2006) Detection of orchid Phytophthora disease by nested PCR. Bot Stud 47, 379-87.

21. Chowdappa P, Brayford D, Smith J, Flood J (2003) Identification of Phytophthora species affecting plantation crops by RFLP of PCR-amplified internal transcribed spacer regions of ribosomal RNA. Curr Sci $\mathbf{8 5}$, 34-6.

22. Bowman KD, Albrecht U, Graham JH, Bright DB (2007) Detection of Phytophthora nicotianae and P. palmivora in citrus roots using PCR-RFLP in comparison with other methods. Eur J Plant Pathol 119, 143-58.

23. Churngchow N, Rattarasarn M (2000) The elicitin secreted by Phytophthora palmivora, a rubber tree pathogen. Phytochemistry 54, 33-8. 
24. Chirapongsatonkul N, Nak-udom P, Churngchow N (2008) Defence responses of calli and seeds of Hevea brasiliensis to zoospores and the elicitin of Phytophthora palmivora. $J$ Phytopathol 156, 732-41.

25. Kwok S, Higuchi R (1989) Avoiding false positives with PCR. Nature 339, 237-8.

26. Vangrysperre W, De Clercq K (1996) Rapid and sensitive polymerase chain reaction based detection and typing of foot-and-mouth disease virus in clinical samples and cell culture isolates, combined with a simultaneous differentiation with other genomically and/or symptomatically related viruses. Arch Virol 141, 331-44.

27. Elnifro EM, Ashshi AM, Cooper RJ, Klapper PE (2000) Multiplex PCR: Optimization and application in diagnostic virology. Clin Microbiol Rev 13, 559-70.

28. Crone M (2012) Persistence of Phytophthora cinnamomi in nature: Biotrophic growth and presence of stromata, oospores and chlamydospores in annual and herbaceous perennial plant species. $\mathrm{PhD}$ thesis, Murdoch Univ.

29. Le Berre JY, Engler G, Panabières F (2007) Exploration of the late stages of the tomato-Phytophthora parasitica interactions through histological analysis and generation of expressed sequence tags. New Phytol 177, 480-92.

30. Drenth A, Guest DI (2004) Diversity and management of Phytophthora in Southeast Asia, Australian Centre for International Agricultural Research Canberra (ACIR) Monograph No. 114.

31. Ellis SD, Boehm MJ (2008) Plants Get Sick Too! An Introduction to Plant Diseases. The fact sheet in plant disease series, The Ohio State Univ, p 401.01. 